2 Humic acid and Fulvic acid Hinder Long-Term Weathering of

3 Microplastics in Lake Water

4 Xiaowei $\mathrm{Wu}^{1,2}$, Peng $\mathrm{Liu}^{3}$, Zhimin Gong ${ }^{1}$, Hanyu Wang ${ }^{1}$, Hexinyue Huang ${ }^{1}$, Yanqi Shi ${ }^{1}$, 5 Xiaoli Zhao ${ }^{2}$, Shixiang Gao*1

6

7 1. State Key Laboratory of Pollution Control and Resource Reuse, School of the

8 Environment, Nanjing University, Nanjing 210093, China

9 2. State Key Laboratory of Environmental Criteria and Risk Assessment, Chinese

10 Research Academy of Environmental Sciences, Beijing, 100012, China

11 3. Key Laboratory of Plant Nutrition and the Agri-environment in Northwest China,

12 Ministry of Agriculture, College of Natural Resources and Environment,

13 Northwest A \& F University, Yangling, 712100, China

14

15

16

17

18

* Corresponding authors E-mail: ecsxg@nju.edu.cn. (S.Gao)

19

20

TEL/FAX: +86- 25- 89680359

21

22 


\section{Summary of contents}

Text:

Text S1. Physicochemical properties of humic acid (SRHA) and fulvic acid (PLFA) used in this study

Text S2. Determination for the concentration of water components in freshwater

Text S3 Calculation of water velocities during MPs photo aging process

Text S4. Identification and quantification of $\mathrm{O}_{2} \cdot-$ and $\bullet \mathrm{OH}$ during PP MPs aging in water

\section{Figure:}

Figure S1. Sampling site for lake water used in this study

Figure S2. a: Photo chemical reactor used for the laboratory accelerating aging experiments in this study; b: Relative spectral energy distribution (mercury lamp) accepted by reaction system during photo chemical experiments (Note that information of photo chemical reactor and relative light energy distribution emission by $500 \mathrm{~W}$ mercury lamp used in this study were supplied by photochemical reactor manufacturer: http://www.njxu.com/)

Figure S3. Consumption of Suwannee River humic acid (SRHA) (a) and Pony Lake fulvic acid (PLFA) (b) during $12 \mathrm{~h}$ UV exposure $\left(\mathrm{C}_{0}\right.$ : TOC value of SRHA/PLFA before UV irradiation; C: TOC value of SRHA/PLFA at specific irradiation time)

Figure S4. Strategies for counting the MPs particle size through ImageJ software (Sample was used for $10 \mathrm{~d}$ UV irradiated PP MPs in Taihu lake (China) water)

Figure S5. a-b: ATR-FTIR spectra for pristine and $12 \mathrm{~d}$ treated aged PP MPs in ultrapure water and freshwater under UV light (a) and darkness (b) conditions.

Figure S6. Photo degradation products produced by PP MPs during aging process in water

Figure S7. Variations for surface morphology of pristine MPs and aged PP MPs in ultrapure water and freshwater under UV light and darkness conditions (a: pristine PP MPs in ultrapure water, b: aged PP MPs after $12 \mathrm{~d}$ of UV irradiation in ultrapure water, c: aged PP MPs treated in darkness conditions for $12 \mathrm{~d}$ in ultrapure water, $\mathrm{d}$ : pristine PP MPs in freshwater, b: aged PP MPs after $12 \mathrm{~d}$ of UV irradiation in freshwater, $\mathrm{c}$ : aged PP MPs treated in darkness conditions for $12 \mathrm{~d}$ in freshwater)

Figure S8. a: Self-degradation of NB under darkness conditions; b: Evidence of $\mathrm{O}_{2}{ }^{-}$ production via XTT $(400 \mu \mathrm{M})$ formazan formation in suspensions for PP MPs in ultrapure water, SRHA, and PLFA contained aqueous solution within 50 min of dark treatment.

Figure S9. UV-vis full scan (200 nm-800 nm) spectra of SRHA and PLFA 
59 Figure S10. 3D-EEM spectra for SRHA (a) and PLFA (b)

60 Figure S11. Light shielding factors for SRHA (gray line) and PLFA (red line) at 61 different concentration intervals

62 Table:

63 Table S1. Characterization of SRHA and PLFA

64

65

66

67 
68

80

81

82

83

\section{Text S1. Physicochemical properties of humic acid (SRHA) and fulvic acid (PLFA)}

used in this study

The molecular weight related $\mathrm{E}_{2} / \mathrm{E}_{3}$, absorbance ratio of $254 \mathrm{~nm}$ to that in $365 \mathrm{~nm},{ }^{1}$ of SRHA $(3.37 \pm 0.015)$ was lower than PLFA $(4.51 \pm 0.034)$ (Table S1) based on the UV-vis full scan results (Figure S9). The content of aromatic moieties determined by $\mathrm{SUVA}_{254}$, the absorbance of $254 \mathrm{~nm}$ to the concentration of humic acid and fulvic acid (10 mg C/L used in this work), ${ }^{2}$ showed that the SUVA 254 of SRHA and PLFA were $2.45 \pm 0.001 \mathrm{~m}^{-1} \mathrm{~L} \mathrm{mg} \mathrm{C}^{-1}$ and $1.17 \pm 0.001 \mathrm{~m}^{-1} \mathrm{~L} \mathrm{mg} \mathrm{C}^{-1}$, respectively (Table S1). 3D-EEM of humic acid and fulvic acid showed absorption region at Ex/Em: 350 $\mathrm{nm} / 450 \mathrm{~nm}$ and Ex/Em: $230 \mathrm{~nm} / 450 \mathrm{~nm}$, referring to the humic and fulvic acid substances contained in SRHA (Figure S10a) and PLFA (Figure S10b). 
95

96

97

98

\section{Text S2. Determination for the concentration of water components in freshwater} The concentration of total organic carbon (TOC) in studied freshwater was determined using a TOC analyzer (element, Germany). The concentration of carbonate $\left(\mathrm{CO}_{3}{ }^{2-}\right)$, nitrate $\left(\mathrm{NO}_{3}^{-}\right)$, chloride ion $\left(\mathrm{Cl}^{-}\right)$, bromide ion $\left(\mathrm{Br}^{-}\right)$in freshwater matrices was determined by ion chromatography analyzer (ICS 5000, Thermo). The detect conditions were: column: IonPac AS19 $(4 \times 250 \mathrm{~mm})$ analytical column; suppressor: AERS-500 2-mm; mobile phase: $\mathrm{KOH}$ (10 mM, generated by EGC-KOH eluent generator); injection volume: $25 \mu \mathrm{L}$; flow rate: $0.38 \mathrm{~mL} / \mathrm{min}$. Other water components, including $\mathrm{pH}(7.25 \pm 0.28)$, conductivity $(407 \pm 8.14 \mu \mathrm{s} / \mathrm{cm})$, salinity $(0.20 \pm 0.001 \%$ o $)$ and Total dissolved solids (TDS) $(273 \pm 4.58 \mathrm{mg} / \mathrm{L})$ were detected by pH/Conductivity meter (MP521, Sanxin, China). 
Wave, wind, or tide induced mechanical forces (i.e., shear stress forces) may able

101 to induce the fragmentation of MPs during aging process in water. ${ }^{3,4}$ In this study, to

102 simulate the disturbance of wave wind, or tide on the aging of MPs in field water

103 environment. A mechanical stirrer A magnetic stirrer was placed in the silica tube and 104 stirred at $700 \mathrm{rad} / \mathrm{min}$. The water velocity induced by mechanical stirrer was calculated 105 in eqs $1:^{5}$ process. $\mathrm{n}$ is the $\mathrm{n}_{\mathrm{s}}$ is the rotating speed of mechanical stirrer, which was $700 \mathrm{rad} / \mathrm{min}$, equal to $11.67 \mathrm{rad} / \mathrm{s}$ in this study. The calculated water velocity was $2.97 \mathrm{~m} / \mathrm{s}$, which was comparable and slightly higher than that in Dongting lake $(\mathrm{V}=2.11 \mathrm{~m} / \mathrm{s})$, China, according to previous literature. ${ }^{6}$ 
Text S4. Identification and quantification of $\mathrm{O}_{2}{ }^{--}$and $\bullet \mathrm{OH}$ during PP MPs aging in water

$\mathbf{O}_{2}{ }^{--}$determination: To clarify the impact mechanism of humic acid and fulvic acid on the formation capacity for $\mathrm{O}_{2}{ }^{-}$during MPs aging process, we firstly compared the formation capacity of $\mathrm{O}_{2}{ }^{--}$by PP MPs, SRHA, and PLFA. Production of $\mathrm{O}_{2}{ }^{--}$during photo aging of PP MPs in water was probed by XTT. $400 \mu \mathrm{M}$ XTT was added into reaction system contained $0.5 \mathrm{~g}$ PP MPs, $10 \mathrm{mg}$ C/L SRHA or $10 \mathrm{mg}$ C/L PLFA and irradiated for $50 \mathrm{~min}$. The impact of NOM on the formation capacity of $\mathrm{O}_{2}{ }^{-}$by PP MPs was also compared. $400 \mu \mathrm{M}$ of XTT was added into a $60 \mathrm{~mL}$ of quartz tube containing $20 \mathrm{~mL} 10 \mathrm{mg}$ C/L SRHA, $10 \mathrm{mg} \mathrm{C/L}$ PLFA, and ultrapure water, and irradiated for 50 min. The concentration of XTT formazan, the reaction product of XTT with $\mathrm{O}_{2}{ }^{--}$under light irradiation, was determined using a ultraviolet-visible spectrum (UV-vis, Cary 100, USA) at $470 \mathrm{~nm}$ (extinction coefficient: 21,600 $\left.\mathrm{M}^{-1} \mathrm{~cm}^{-1}\right){ }^{7}$ The cumulated concentration of $\mathrm{O}_{2}{ }^{--}$was detected at $0,10,20,30,40$, and 50 min, which was calculated as 2 folds of the concentration of XTT formazan. ${ }^{8}$

-OH determination: $\mathrm{NB}$ was used as probe compound to quantify the produced $\bullet \mathrm{OH}$ during PP MPs photo aging process. ${ }^{9}$ In accordance with $\mathrm{O}_{2}{ }^{-}$, we accessed the formation capacity of $\bullet \mathrm{OH}$ by PP MPs, SRHA, and PLFA firstly. $3 \mathrm{mM}$ of NB was added into a $20 \mathrm{~mL}$ reaction system, which contained $0.5 \mathrm{~g}$ PP MPs, or $10 \mathrm{mg} \mathrm{C} / \mathrm{L}$ SRHA, or $10 \mathrm{mg} \mathrm{C/L} \mathrm{PLFA} \mathrm{and} \mathrm{irradiated} \mathrm{for} 5 \mathrm{~h}$. Additionally, in order to clarify the impact of NOM on the formation capacity of $\bullet \mathrm{OH}$ by PP MPs, we exposed $3 \mathrm{mM}$ NB and $0.5 \mathrm{~g}$ PP MPs in $20 \mathrm{~mL}$ solutions containing ultrapure water, or $10 \mathrm{mg} \mathrm{C} / \mathrm{L}$ SRHA, 
139 or $10 \mathrm{mg} \mathrm{C/L} \mathrm{PLFA} \mathrm{for} 5 \mathrm{~h}$ irradiation. After UV exposure, $0.5 \mathrm{~mL}$ suspension was 140 removed from the reaction system and filtrated through a $0.45 \mu \mathrm{m} \mathrm{GF/F} \mathrm{membrane}$ 141 prior instrumental analysis. The residue concentration of NB within the reaction system 142 at different irradiation time (i.e., 0, 1, 2, 3, 4, and 5 h) was determined by Agilent 1200 143 series HPLC coupled with a UV detector. The separation column was an Agilent 144 Eclipse XDB-C18 reversed phase column $(5 \mu \mathrm{m} \times 250 \mathrm{~mm} \times 4 \mathrm{~mm})$. The mobile phase 145 was acetonitrile and ultrapure water $(60: 40)$ with a flow rate of $0.5 \mathrm{~mL} / \mathrm{min}$. The 146 detection wavelength, injection volume, and temperature were set at $263 \mathrm{~nm}, 20 \mu \mathrm{L}$, 147 and $30^{\circ} \mathrm{C}$, respectively. ${ }^{10}$ 
151 Figure S1. Sampling site for freshwater used in this study

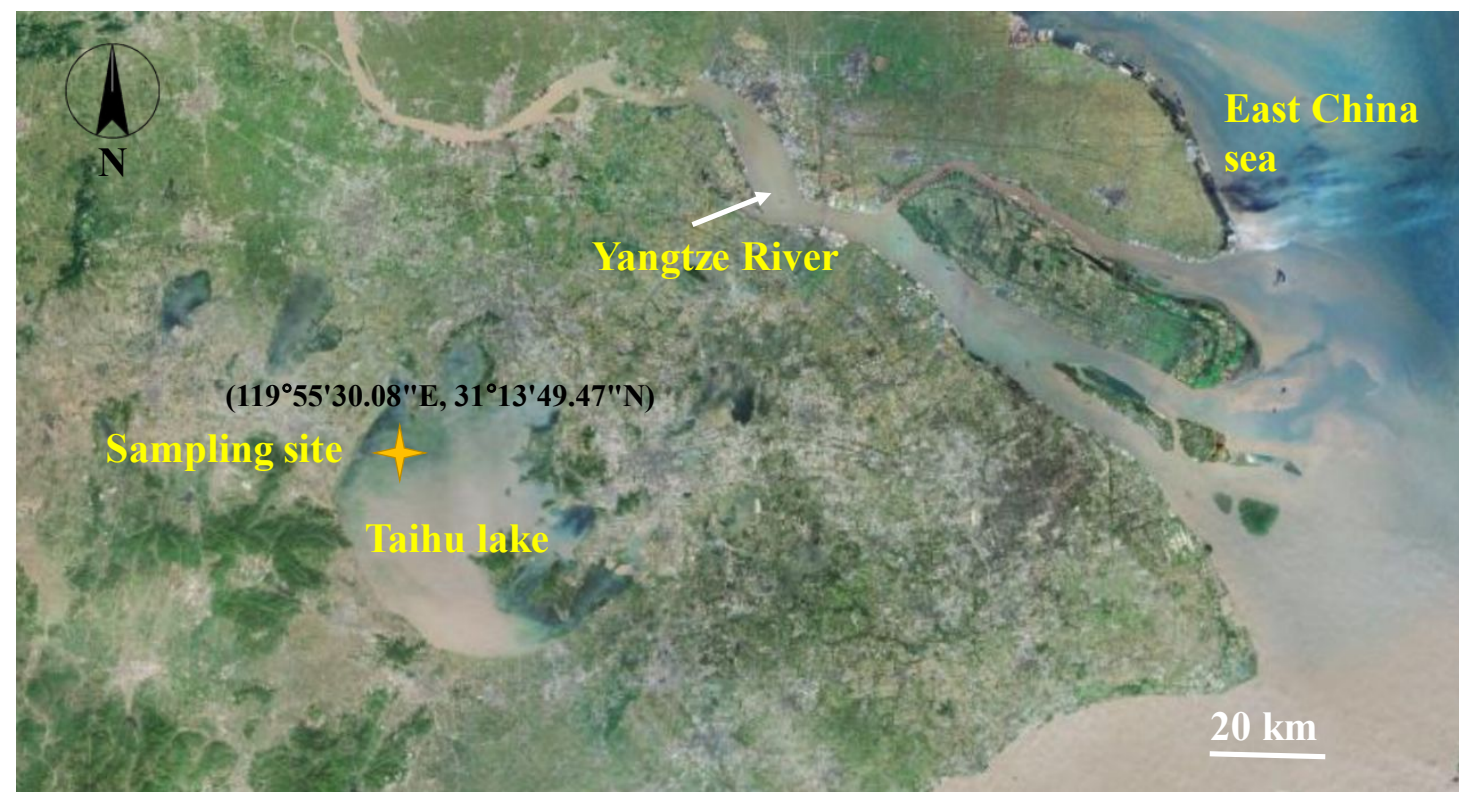

153

154

155

156

157

158 
Figure S2. a: Photo chemical reactor used for the laboratory accelerating aging experiments in this study; $b$ : Relative spectral energy distribution (mercury lamp) accepted by reaction system during photo chemical experiments (Note that information of photo chemical reactor and relative light energy distribution emission by $500 \mathrm{~W}$ mercury lamp used in this study were supplied by photochemical reactor manufacturer: http://www.njxu.com/)

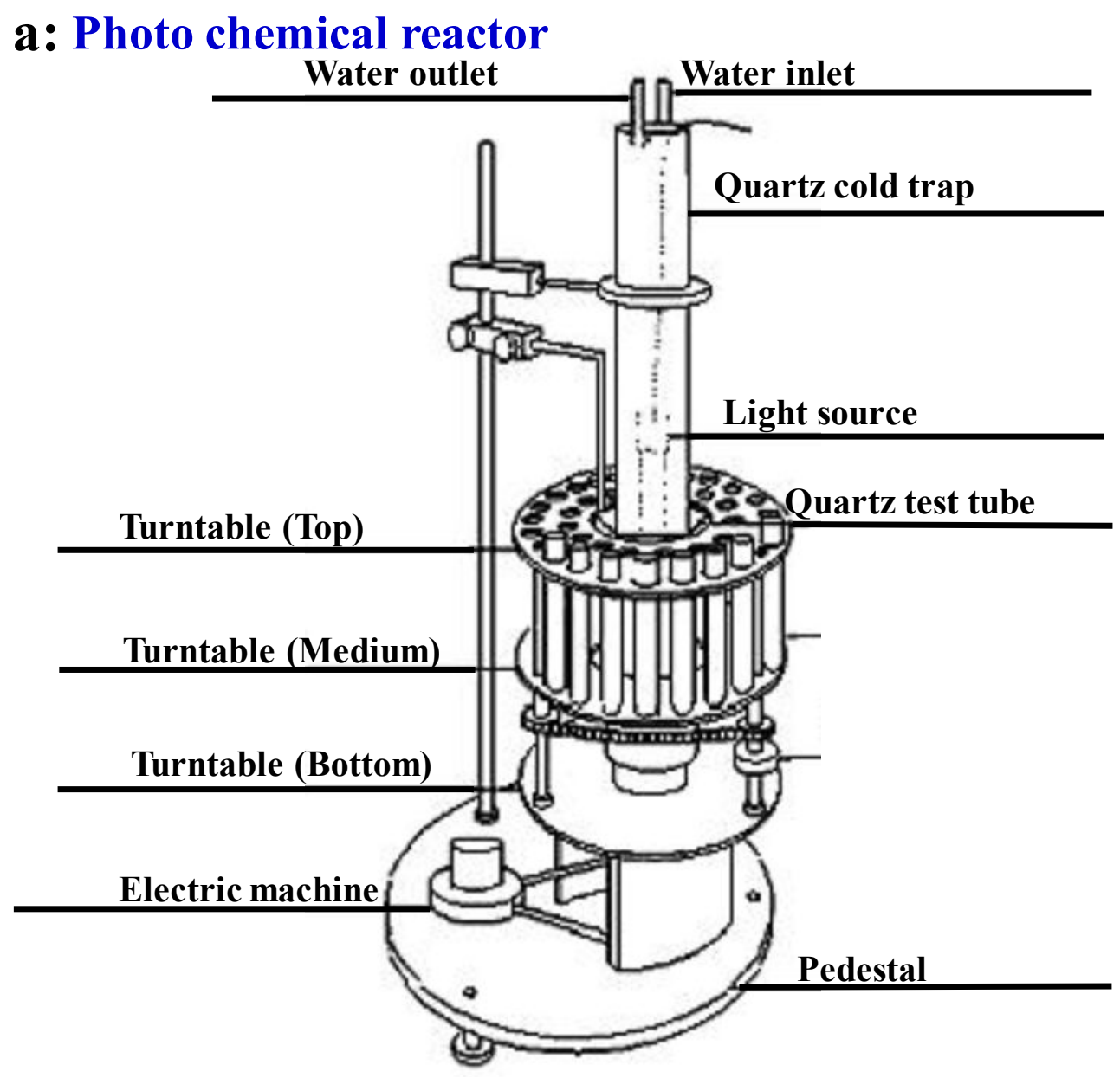

b : Relative spectral energy distribution (mercury lamp) accepted by reaction system during photo chemical experiments

\begin{tabular}{|c|c|c|c|c|c|c|c|c|c|}
\hline $\begin{array}{c}\text { Wavelength } \\
\text { (nm) }\end{array}$ & $265.2-265.5$ & 296.7 & $302.2-302.8$ & $312.6-313.2$ & $365-366.3$ & $404.5-407.8$ & 435.8 & 546.1 & $577-579$ \\
\hline $\begin{array}{c}\text { Relative } \\
\text { energy (\%) }\end{array}$ & 15.3 & 16.6 & 23.9 & 49.9 & 100 & 42.2 & 77.5 & 93 & 76.5 \\
\hline
\end{tabular}


Figure S3. Consumption of Suwannee River humic acid (SRHA) (a) and Pony Lake fulvic acid (PLFA) (b) during $12 \mathrm{~h}$ UV exposure $\left(\mathrm{C}_{0}\right.$ : TOC value of SRHA/PLFA before UV irradiation; C: TOC value of SRHA/PLFA at specific irradiation time)

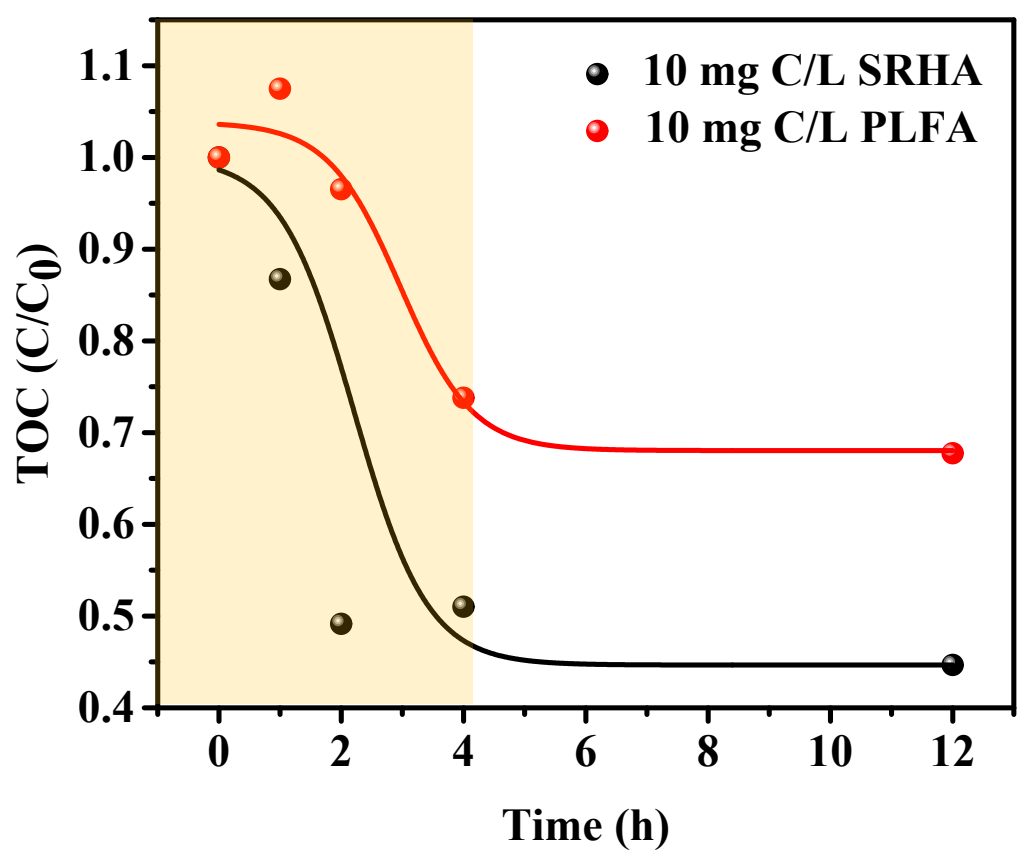

Note that most of chemicals was mineralized dramatically at $0-4 \mathrm{~h}$ of UV irradiation, which may due to the presence of hydroxyl, carbonyl, and carboxylic groups related low molecular phenol, hydroxybenzoic acid (HBA), and benzoquinone (BQ) in humic acid and fulvic acid which were readily to be degraded under light irradiation. ${ }^{11}$ While the consumption of chemicals keeps at a steady state at 4-12 h may assign to the residue high molecular substances (i.e., proteins, polysaccharides, and peptides) in HA and FA, which were hardly to be degraded under light irradiation ${ }^{12}$ 
182 Figure S4. Strategies for counting the MPs particle size through ImageJ software

183 (Sample was used for $10 \mathrm{~d}$ UV irradiated PP MPs in Taihu lake (China) water)

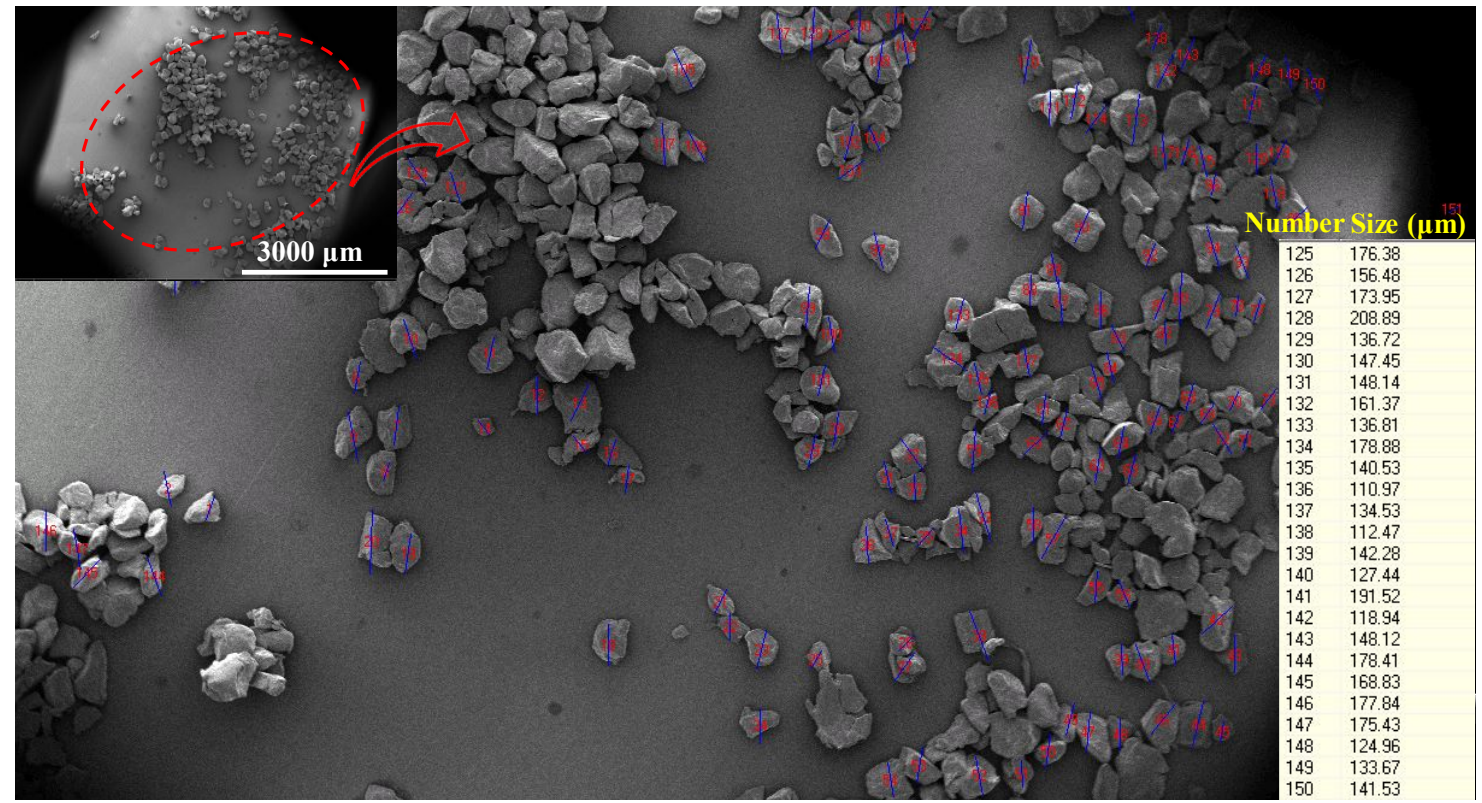

185

186 
Figure S5. a-b: ATR-FTIR spectra for pristine and $12 \mathrm{~d}$ treated aged PP MPs in ultrapure water and freshwater under UV light (a) and darkness (b) conditions.

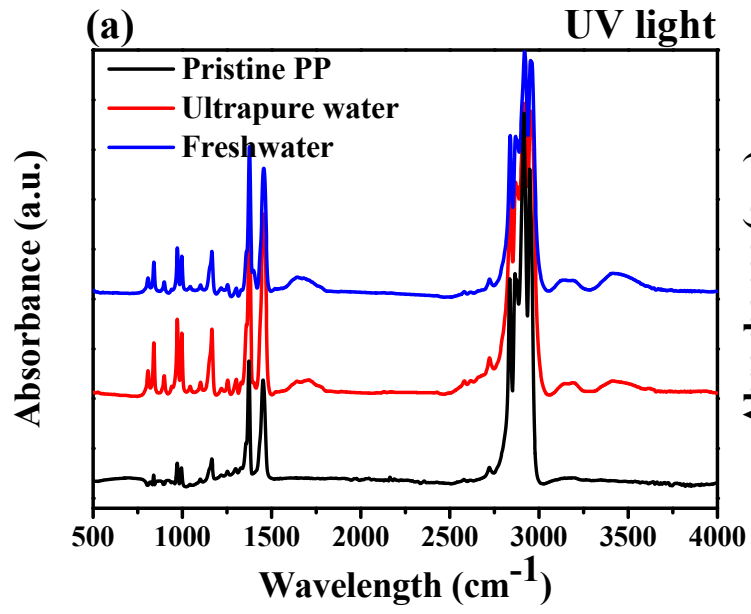

(b) Darkness

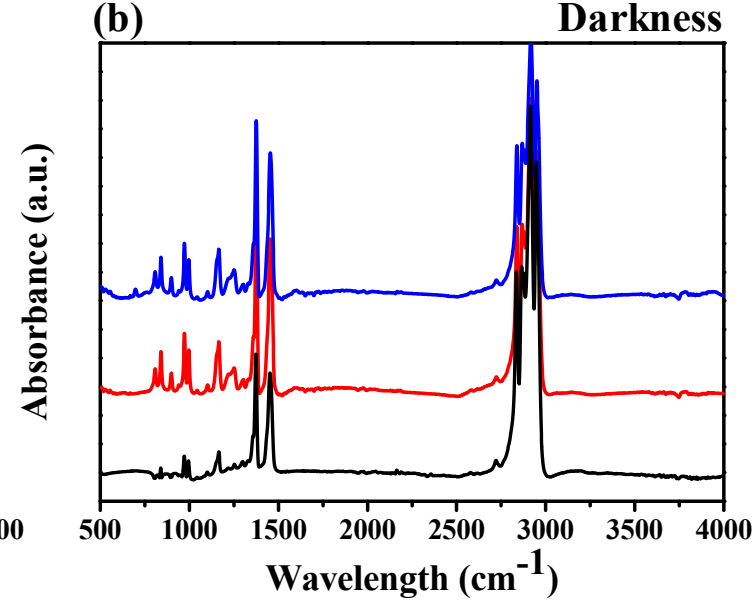

190 


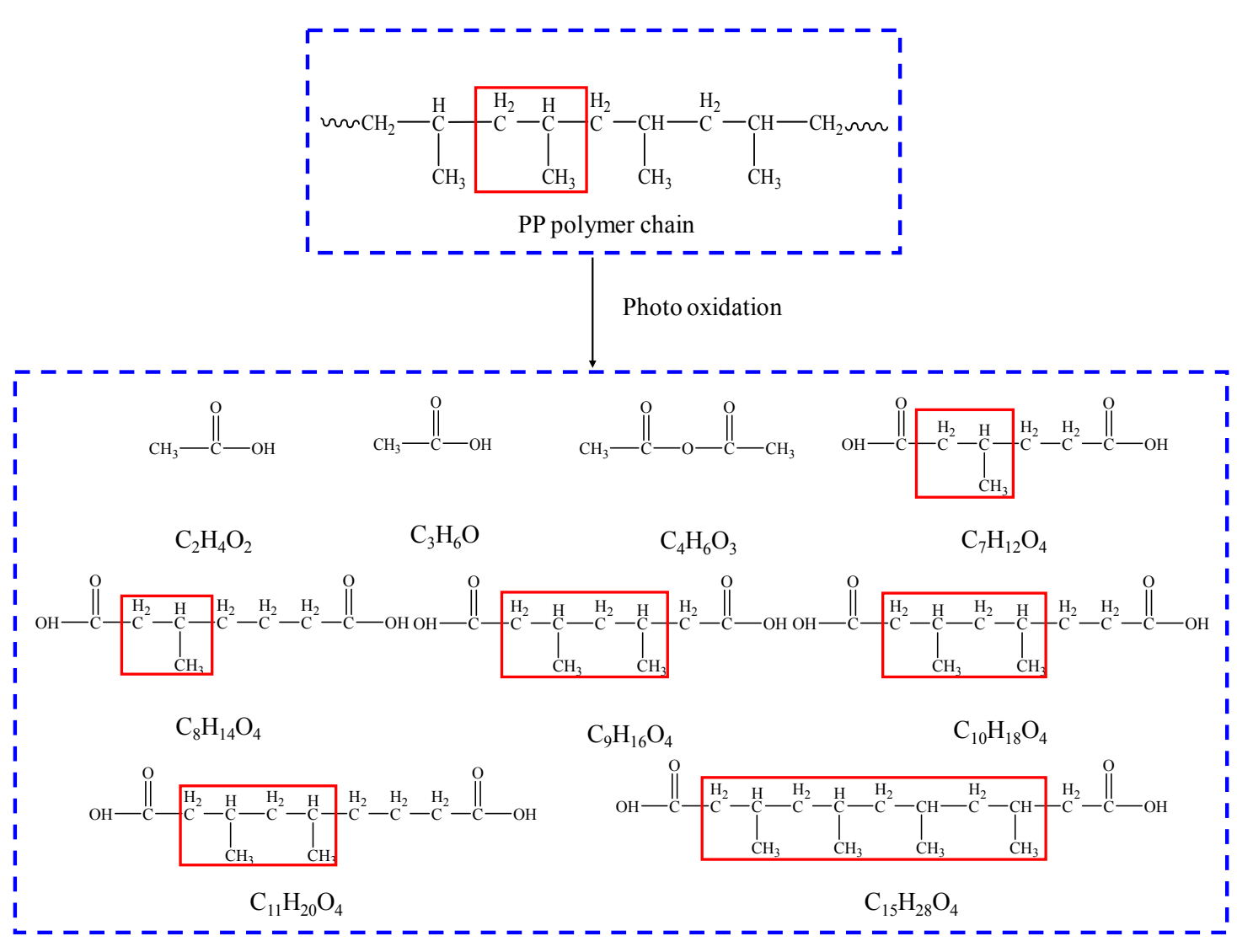


Figure S7. Variations for surface morphology of pristine MPs and aged PP MPs in ultrapure water and freshwater under UV light and darkness conditions (a: pristine PP MPs in ultrapure water, b: aged PP MPs after $12 \mathrm{~d}$ of UV irradiation in ultrapure water, c: aged PP MPs treated in darkness conditions for $12 \mathrm{~d}$ in ultrapure water, $\mathrm{d}$ : pristine PP MPs in freshwater, b: aged PP MPs after $12 \mathrm{~d}$ of UV irradiation in freshwater, c: aged PP MPs treated in darkness conditions for $12 \mathrm{~d}$ in freshwater)

207
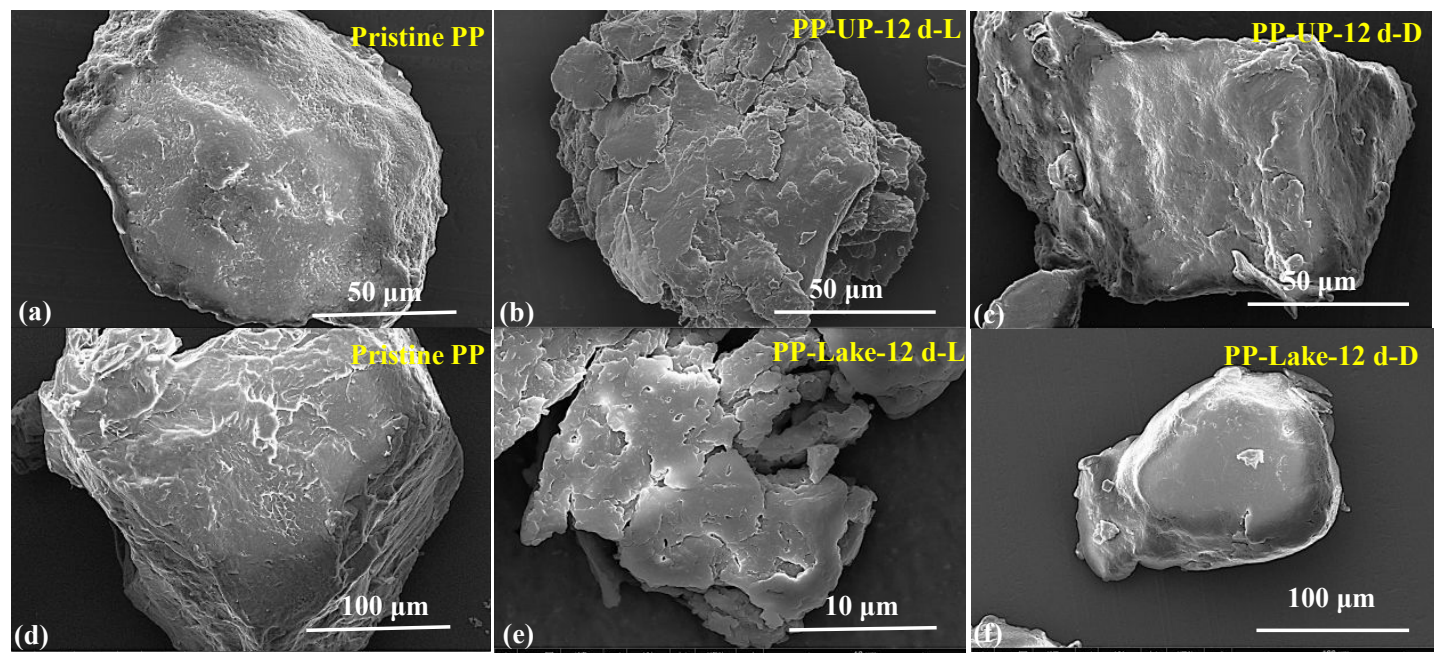

209 
212 Figure S8. a: Self-degradation of NB under darkness conditions; b: Evidence of $213 \mathrm{O}_{2}{ }^{--}$production via XTT $(400 \mu \mathrm{M})$ formazan formation in suspensions for PP MPs 214 in ultrapure water, SRHA, and PLFA contained aqueous solution within 50 min 215 of dark treatment.
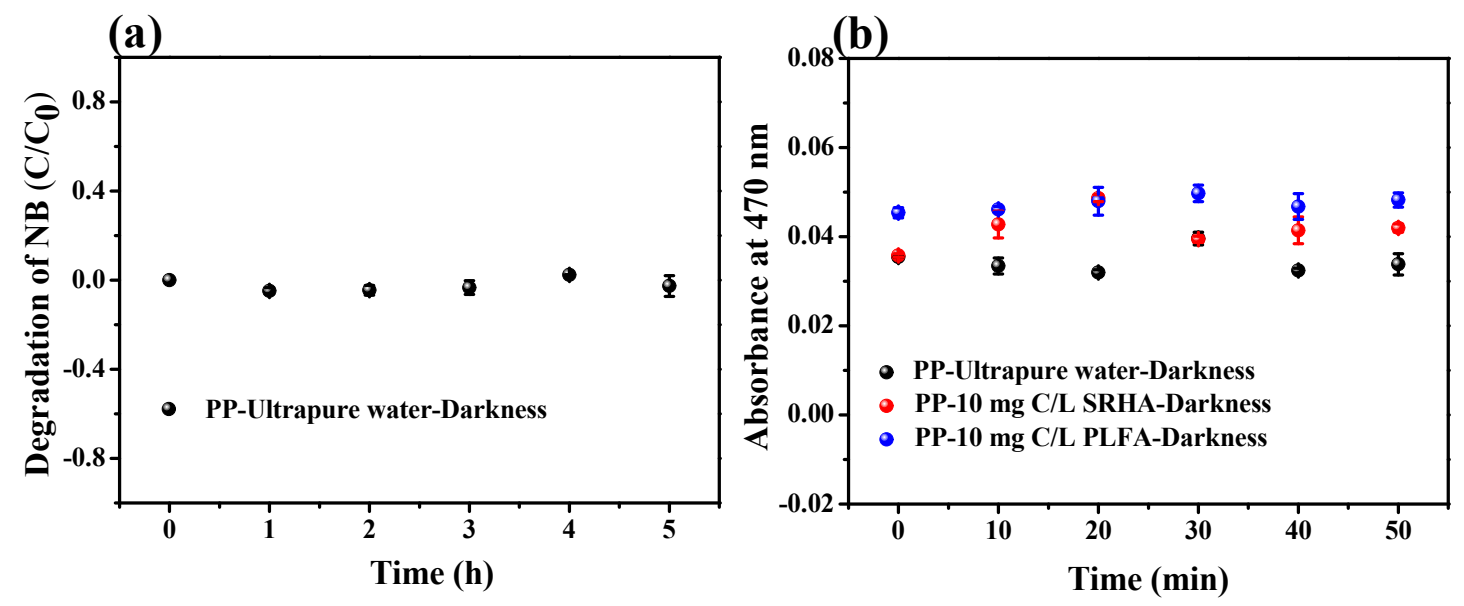
220 Figure S9. UV-vis full scan (200 $\mathbf{~ m m - 8 0 0 ~} \mathbf{n m})$ spectra of SRHA and PLFA

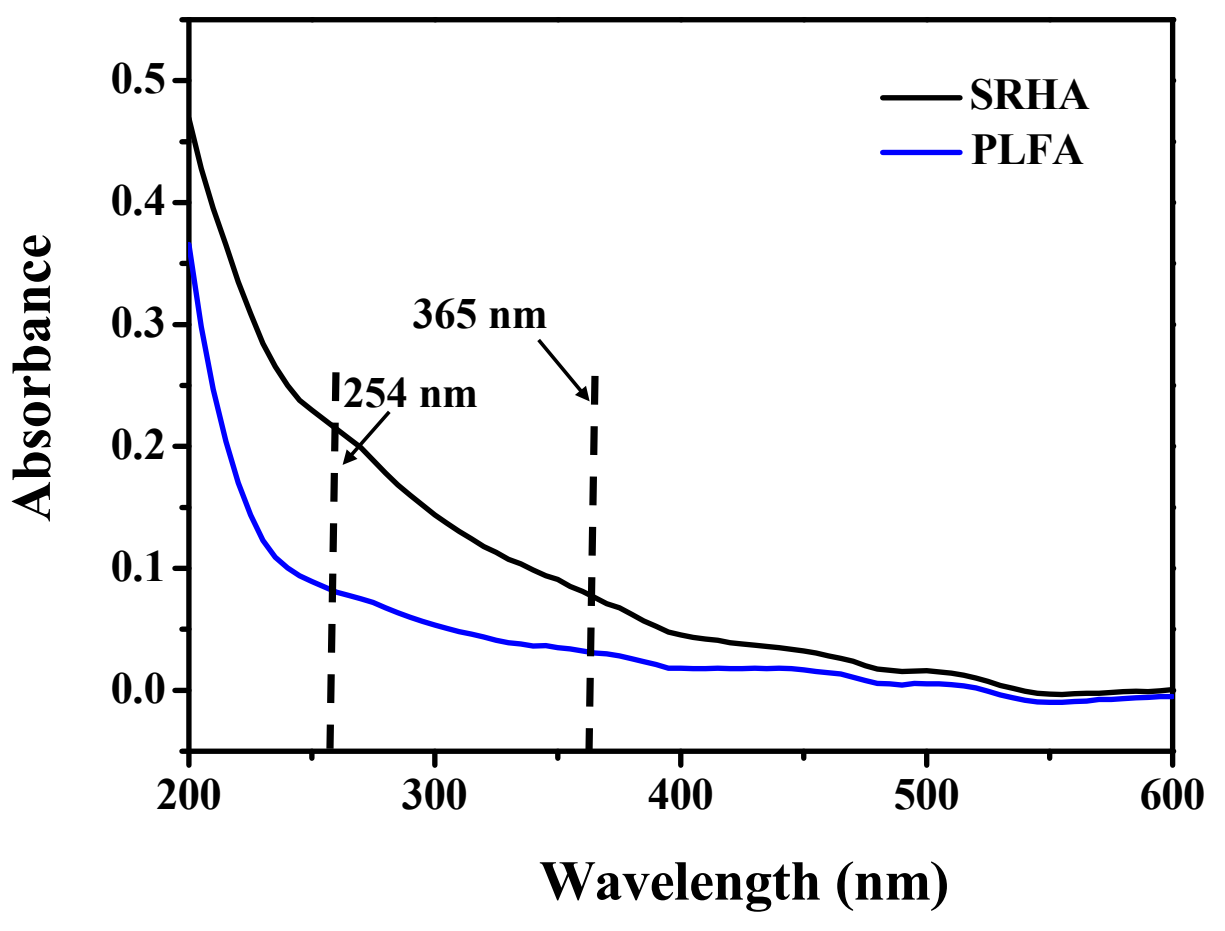

222 
Figure S10. 3D-EEM spectra for SRHA (a) and PLFA (b)
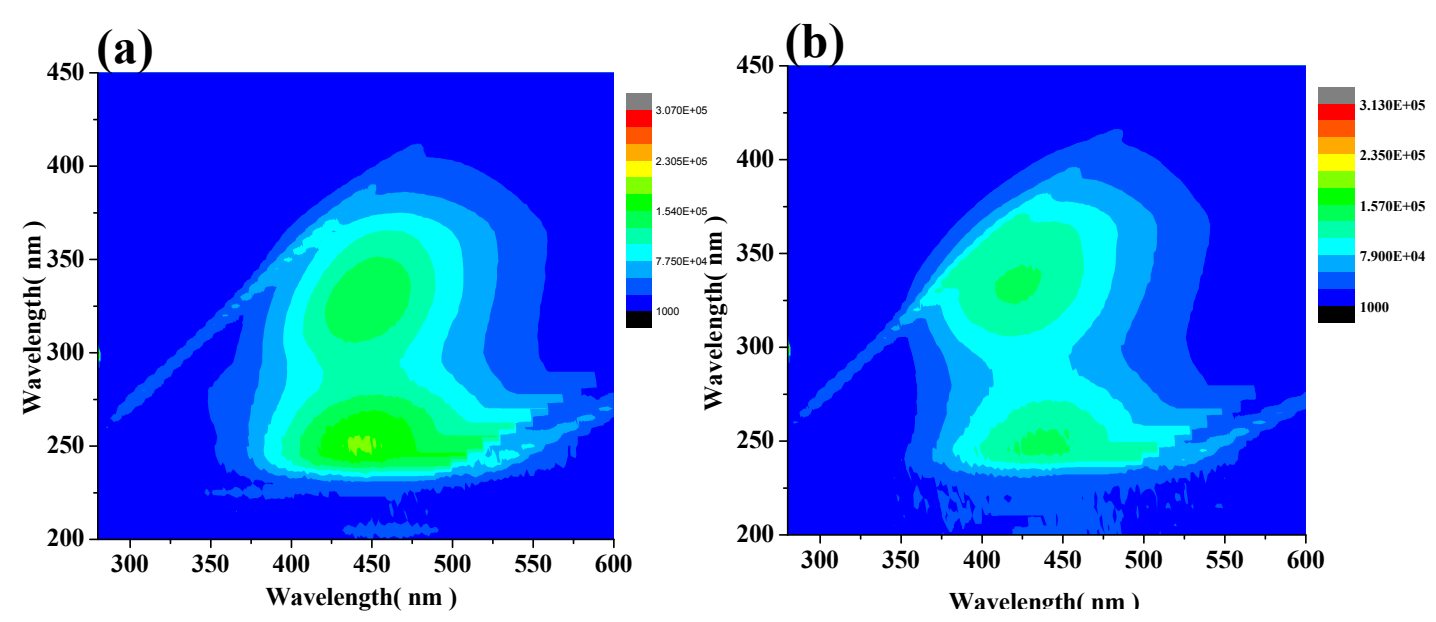
Figure S11. Light shielding factors for SRHA (gray line) and PLFA (red line) at 227 different concentration intervals

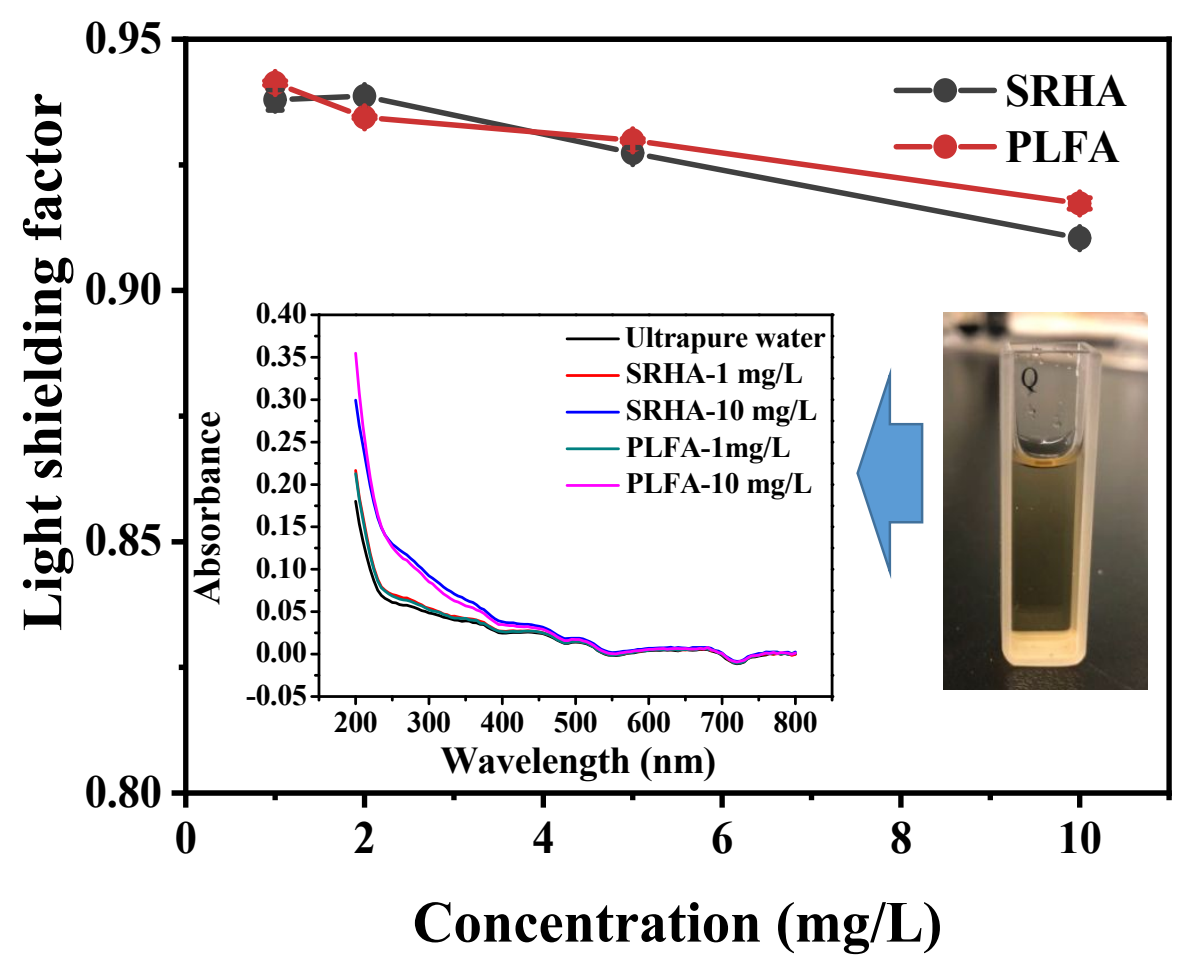




\begin{tabular}{|c|c|c|c|c|c|c|c|c|}
\hline NOM & $\begin{array}{l}\text { TOC } \\
(\mathrm{mg} \\
\mathrm{C} / \mathrm{L})\end{array}$ & $\begin{array}{l}\text { UVA at } 254 \mathrm{~nm} \\
\left(\times 10^{-2} \mathrm{~cm}^{-1}\right)\end{array}$ & $\begin{array}{c}\operatorname{SUVA}_{254}\left(\mathrm{~m}^{-1}\right. \\
\left.\mathrm{L} \mathrm{mgC}^{-1}\right)\end{array}$ & UVA at 365 & $m\left(\times 10^{-2}\right.$ & \multicolumn{3}{|c|}{$\mathbf{E}_{2} / \mathbf{E}_{3}$} \\
\hline SRHA & 10 & $\begin{array}{c}24.52 \pm \\
0.017\end{array}$ & $\begin{array}{r}2.45 \pm \\
0.001\end{array}$ & $7.26 \pm$ & 0.03 & 3.37 & \pm & 0.015 \\
\hline PLFA & 10 & $\begin{array}{c}11.78 \pm \\
0.015\end{array}$ & $\begin{array}{r}1.17 \pm \\
0.001\end{array}$ & 2.61 & 0.017 & 4.51 & \pm & 0.034 \\
\hline
\end{tabular}

232

233 


\section{References}

1. Dalrymple, R.; Carfagno, A.; Sharpless, C., Correlations between dissolved organic matter optical properties and quantum yields of singlet oxygen and hydrogen peroxide. Environ. Sci. Technol. 2010, 44, 5824-5829.

2. Weishaar, J.; Aiken, G.; Bergamaschi, B.; Fram, M.; Fujii, R.; Mopper, K., Evaluation of specific ultraviolet absorbance as an indicator of the chemical composition and reactivity of dissolved organic carbon. Environ. Sci. Technol. 2003, 37, 4702-4708.

3. Enfrin, M.; Lee, J.; Gibert, Y.; Basheer, F.; Kong, L.; Dumee, L., Release of hazardous nanoplastic contaminants due to microplastics fragmentation under shear stress forces. J. Hazard. Mater. 2020, 384, 121393.

4. Song, Y.; Hong, S.; Jang, M.; Han, G.; Jung, S.; Shim, W., Combined effects of UV exposure duration and mechanical abrasion on microplastic fragmentation by polymer type. Environ. Sci. Technol. 2017, 51, (8), 4368-4376.

5. Yang, L.; Tan, Y., On curve fitting of flow rate and speed of rotor flow meter Hunan water conservancy and hydropower 2019, 4, 47-49.

6. Li, D., The research on nitrogen and phosphor use nutrient Characteristic of Poyang lake. . East China Institute of Technology 2014.

7. Chen, C.; Jafvert, C., Photoreactivity of carboxylated single-walled carbon nanotubes in sunlight: reactive oxygen species production in water Environ. Sci. Technol. 2010, 44, 6674-6679.

8. Sutherland, M.; Learmonth, B., The tetrazolium dyes MTS and XTT provide new quantitative assays for superoxide and superoxide dismutase. Free. Radic. Res. 1997, 27, (3), 283-289.

9. Kong, X.; Jiang, J.; Ma, J.; Yang, Y.; Liu, W.; Liu, Y., Degradation of atrazine by UV/chlorine: Efficiency, influencing factors, and products. Water. Res. 2016, 90, 15-23.

10. Ye, B.; Li, Y.; Chen, Z.; Wu, Q.; Wang, W.; Wang, T.; Hu, H., Degradation of polyvinyl alcohol (PVA) by UV/chlorine oxidation: Radical roles, influencing factors, and degradation pathway. Water. Res. 2017, 124, 381-387.

11. Wang, M.; Xiang, X.; Zuo, Y.; Peng, J.; Lu, K.; Dempsey, C.; Liu, P.; Gao, S., Singlet oxygen production abilities of oxidated aromatic compounds in natural water. Chemosphere 2020, 258, 127308. 12. Zhang, J.; Song, F.; Li, T.; Xie, K.; Yao, H.; Xing, B.; Li, Z.; Bai, Y., Simulated photo-degradation of dissolved organic matter in lakes revealed by three-dimensional excitation-emission matrix with regional integration and parallel factor analysis. J. Environ. Sci. (China) 2020, 90, 310-320.

13. Liu, P.; Wu, X.; Peng, J.; Wang, H.; Shi, Y.; Huang, H., Critical effect of iron red pigment on photo aging behavior of polypropylene microplastics in artificial seawater. J. Hazard. Mater. 2021, 404, 124209. 